\title{
In vivo Toxicopathological Evaluation of a Purified Bioflocculant Produced by Arthrobacter humicola
}

\author{
Mayowa Oladele Agunbiade ${ }^{1,2^{*}}$, Sabiu Saheed ${ }^{1,3}$, Esta Van Heerden ${ }^{1,4}$, Carolina Henritta Pohl'
}

\section{Mayowa Oladele Agun- biade $^{1,2^{*}}$, Sabiu Saheed ${ }^{1,3}$, Esta Van Heerden ${ }^{1,4}$, Caro- lina Henritta Pohl ${ }^{1}$}

\begin{abstract}
'Department of Microbial, Biochemical and Food Biotechnology, University of the Free State, P.O. Box 339, Nelson Mandela Drive, Bloemfontein, 9301, SOUTH AFRICA ${ }^{2}$ Biocatalysis and Technical Biology Research Group, Institute of Biomedical and Microbial Biotechnology, Cape Peninsula University of Technology, SOUTH AFRICA

${ }^{3}$ Faculty of Applied Sciences, Durban University of Technology, SOUTH AFRICA

${ }^{4}$ iWater Pyt Limited, Walter Sisulu 5, Bloemfontein, SOUTH AFRICA
\end{abstract}

\section{Correspondence}

\section{Dr. Mayowa Agunbiade}

Department of Microbial, Biochemical and Food Biotechnology, University of the Free State, P.O. Box 339, Nelson Mandela Drive, Bloemfontein, 9301, SOUTH AFRICA.

Phone no : +27717670208

E-mail: mayorlala@gmail.com

History

- Submission Date: 05-11-2018;

- Review completed: 07-02-2019;

- Accepted Date: 17-02-2019

DOI : 10.5530/pj.2019.11.77

Article Available online

http://www.phcogj.com/v11/i3

Copyright

C 2019 Pharmacognosy Journal. This is an open-access article distributed under the terms of the Creative Commons Attribution 4.0 International license.

\begin{abstract}
Introduction: In spite of the commendable flocculating activities of microbial flocculants, a good number of them potentiate significant toxicity. This study evaluated the in vivo toxicological implications of treatment with the Purified bioflocculant (PB) from Arthrobacter humicola using OECD guidelines. Materials and Methods: In the acute toxicity assessment, a single oral administration of $2000 \mathrm{mg} / \mathrm{kg}$ body weight (b.w.) of PB was given to the Wistar rats and the animals were observed for 2 weeks. The daily dose toxicity testing was performed through daily oral treatment with graded doses $(50,200$ and $500 \mathrm{mg} / \mathrm{kg} \mathrm{b.w}$.) of PB for 4 weeks. Clinical signs of toxicity, behavioral changes, hematological and biochemical parameters were thereafter evaluated. Results: PB at $2000 \mathrm{mg} / \mathrm{kg} \mathrm{b.w}$. produced no treatment-mediated signs of toxicity, behavioral changes or mortality in the animals. Thus, its no-observed-adverse-effect level was estimated to be above $2000 \mathrm{mg} / \mathrm{kg} \mathrm{b.w}$. In the repeated dose toxicity testing, treatments with PB also revealed no significant differences in the feeding patterns, lipid profiles, hematological and clinical biochemistry parameters when compared with the control group. Although, at $500 \mathrm{mg} / \mathrm{kg} \mathrm{b.w.} \mathrm{PB,} \mathrm{a} \mathrm{significant} \mathrm{increase} \mathrm{was} \mathrm{observed}$ in the serum activities of alkaline phosphatase, nonetheless, cage side observations recorded no treatment-induced signs of toxicity and macro-histopathological examinations of all the investigated organs also revealed no obvious morphological changes. Conclusion: The overall results suggested that PB was well tolerated by the animals and is endowed with monosaccharides bearing functional groups of flocculation importance, thus, suggesting its potential application as a safe actinomycetes bioflocculant for water treatment.

Key words: Actinomycetes, Arthrobacter humicola, Bioflocculant, Hematological, Polysaccharides, Wastewater treatment.

Key Messages: The Purified bioflocculant from Arthrobacter humicola is rich in monomers bearing functional groups of flocculation importance and could be harnessed for water treatment due to its non-toxic tendency.
\end{abstract}

\section{INTRODUCTION}

Flocculation is a process whereby flocs are formed through the agglomeration of colloids and suspended particles in a suspension with the aid of flocculants. Basically, three types of flocculating agents, namely inorganic flocculants, organic flocculants and natural flocculants have been reported. ${ }^{1}$ Microbial flocculants are extracellular polymeric substances containing glycoproteins, polysaccharides and proteins produced by microorganisms during their active secretion. ${ }^{2}$ Bioflocculants are biodegradable, harmless and free of secondary pollution and they have gained global importance as a replacement for traditional flocculants like polyaluminium chloride, ferric chloride, aluminium sulphate and polyacrylamide. Bioflocculant producing organisms have been isolated from soil samples, river water, activated sludge, dams and salt soil sample., ${ }^{3,4}$ Literature search has revealed microbial biopolymers as good anti-bacterial, anti-viral and anti-algal agents and as inducers of microbial aggregation and formation of biofilm. ${ }^{5}$ Furthermore, biofloc-

culants have been successfully adopted in various fields including heavy metals removal, wastewater treatment, fermentation industries, dewaterability of waste sludge, biofuels technology, harvesting of scale microalgae and treatment of estrogens from wastewater. ${ }^{6-8}$ In our previous study, the flocculating activity of bioflocculant produced by Arthrobacter humicola have been reported and the organism demonstrated a unique flocculating potential in sewage wastewater treatment with respect to removal of chemical oxygen demand, biological oxygen demand, turbidity, nitrate and heavy metals respectively. ${ }^{4}$ Since many bacterial extracellular polymeric substances are known to be toxic, it is imperative to determine the toxicity of the unique bio flocculant produced by Arthrobacter humicola. It is also noteworthy that, there is paucity of information on the safety evaluation of bioflocculant produced by actinomycetes. Hence, a detailed toxicological assessment of the bio flocculant produced by Arthrobacter ation of a Purified Bioflocculant Produced by Arthrobacter humicola. Pharmacog J. 2019;11(3):48692 
humicola is paramount prior to large scale production and recommendation for human consumption. It is on this background, that the present study was conceptualized to investigate the effect of oral acute and 4-week daily dose administration of the purified bio flocculant produced by Arthrobacter humicola on the key metabolic markers of Wistar rats.

\section{MATERIALS AND METHODS}

\section{Chemicals, Reagents and Assay Kits}

The chemicals and reagents used were of analytical grade and obtained from Sigma-Adrich Co. St Louis, Missouri, USA, while the water used was glass-distilled. All the assay kits including those for the determination of Total cholesterol (TC), Triacylglycerides (TG), Low-density Lipoprotein Cholesterol (LDL-C), High-Density Lipoprotein Cholesterol (HDL-C), Liver function parameters [Alanine aminotranferase (ALT), Aspartate Aminotransaminase (ALT), Alkaline Phosphatase (ALP), albumin and total protein] and kidney function indices [Blood Urea Nitrogen (BUN), creatinine, calcium and potassium] were products of Randox Laboratory Ltd, Co. Antrim, United Kingdom.

\section{Extraction and purification of bioflocculant}

This assay was done according to the protocol of Chen et al. ${ }^{9}$ and Piyo et al. ${ }^{10}$ with modifications. In brief, after 3 days of fermentation, the culture broth was centrifuged at $8000 \mathrm{rpm}$ for $30 \mathrm{~min}$ to remove bacteria cells. Exactly $1 \mathrm{~L}$ of sterile distilled water was added to the supernatant and further centrifuged at $8000 \mathrm{rpm}$ for $15 \mathrm{~min}$ to remove insoluble substances. Two volumes of ethanol were then added to the supernatant, mixed and allow to stand for $12 \mathrm{~h}$ at $4^{\circ} \mathrm{C}$. The resulting precipitate was vacuum-dried to obtain crude bioflocculant. Subsequently, the crude product was dissolved in distilled water prior to addition of $1 \mathrm{~L}$ of chloroform: n-butyl alcohol (5:2 v/v). The mixture was mixed and gently transferred into separating funnel and allowed to stand for $12 \mathrm{~h}$ at room temperature. Finally, the supernatant was discarded and $2 \mathrm{~L}$ of ethanol were added to recover the precipitate and then lyophilized to obtain the Purified Bioflocculant (PB). The PB was reconstituted in sterile distilled water to give the various concentrations $(\mathrm{mg} / \mathrm{kg}$ body weight of the animals) employed in this study.

\section{Experimental animals}

The thirty (8 weeks old) healthy nulliparous female Wistar rats (Weight range $150 \pm 10.6 \mathrm{~g}$ ) used for this study were housed in hygienic metallic cages kept in a well-aerated room with standard environmental condition (Temperature $23 \pm 1^{\circ} \mathrm{C}$, photoperiod; $12 \mathrm{~h}$ natural light and $12 \mathrm{~h}$ dark; humidity; $45-50 \%)$. The rats were allowed 2 weeks acclimatization period and had ad libitum access to pelleted rat chow and potable water. The cages were cleaned daily and protocols adopted were reviewed and certified in accordance with the guidelines of the National Institute of Health for the Care and Use of Laboratory Animals (\#85-23) ${ }^{11}$ and National Research Council Guide. ${ }^{12}$

\section{Acute toxicological evaluation}

This was performed following the modified method of Organization of Economic Cooperation and Development (OECD) guideline 420 for testing of chemicals OECD. ${ }^{13}$ Ten Wistar rats were first fasted for $18 \mathrm{~h}$ prior to randomization into 2 groups of 5 animals each. The control group received only sterile distilled water, while the solution of $\mathrm{PB}$ was administered orally (Only once) at a single dose of $2000 \mathrm{mg} / \mathrm{kg}$ body weight (b.w.) to the animals in the experimental group. Thereafter, the animals were pertinently observed for the first $24 \mathrm{~h}$, with close monitoring in the first $4 \mathrm{~h}$ and then $24 \mathrm{~h}$ for the next 14 days. All the animals were weighed and subjected to thorough gross necropsy during this period. Behavioral changes, lethargy, depression, salivation, convulsions, tremors, locomotion, bite, sup, diarrhea, weakness, sedation and ailment signs were also monitored. Adopting the method of Ajani et al. ${ }^{14}$ the median Lethal Dose $\left(\mathrm{LD}_{50}\right)$ of PB was thereafter estimated based on the mortality observed in each group. On the $15^{\text {th }}$ day, the rats were humanely euthanized (Halothane anaesthetization) and blood samples were collected by cardiac puncture into non-heparinized and Ethylenediamine Tetra Acetic Acid (EDTA) bottles. The samples were subsequently centrifuged (15000 rpm, $10 \mathrm{~min}$ ) and used for clinical biochemistry and hematological analyses, respectively. The rats were also immediately dissected and the liver and kidneys were excised, freed of fat, blotted with clean towel and weighed. The relative organ-body weight ratios were evaluated and were subsequently fixed in $10 \%$ buffered formalin solution for histopathological examination.

\section{4-week daily oral toxicological assessment}

Twenty rats randomly distributed into 4 groups were used for this study and the protocol conforms to OECD guideline 407 for testing substances OECD. ${ }^{15}$ The control group had 5 animals and received $1 \mathrm{ml}$ distilled water, while groups 2-4 were daily administered with 50, 200 and $500 \mathrm{mg} / \mathrm{kg}$ b.w. PB respectively for 4 weeks. The PB solution was freshly prepared on daily basis and all administrations were done via oral intubation throughout the experimental period. The animals were weighed on weekly basis and also subjected to thorough observations for morbidity, mortality, behavioral changes and possible symptoms of humane end point during this period. Furthermore, the amount of feed and water intakes were determined on daily basis and the average weekly consumption pattern was calculated throughout the investigation period. ${ }^{16}$

At the end of the experimental period, blood samples were similarly collected from overnight fasted animals via cardiac puncture into non-heparinized and EDTA-coated bottles as detailed above (Acute toxicity) and also used for clinical biochemistry and hematological analyses, respectively. The liver and kidneys were removed, weighed and prepared histopathological examinations.

\section{Hematological, clinical biochemistry and histopathological analyses}

The Automated Hematologic Analyzer, Sysmex, KX-21 (Japan) was used to analyze hematological parameters [Red Blood Cell Count (RBC), Hematocrit (HCT), Hemoglobin Concentration ( $\mathrm{Hb})$, Mean Corpuscular Volume (MCV), Mean Corpuscular Hemoglobin (MCH), Platelet (PLT), Mean Corpuscular Hemoglobin Concentration (MCHC), White Blood Cell Count (WBC), lymphocyte count, monocyte count and neutophil counts], while assay kits were employed for serum analyses of lipid profile, liver and kidney function parameters following the procedures described in the respective kit.

For the histopathological examination, the method of Drury and Wallington ${ }^{17}$ was adopted. In brief, tissue pieces of the liver and kidney were washed in normal saline and fixed immediately in 10\% buffered formalin solution for a period of $24 \mathrm{~h}$. They were subsequently dehydrated in graded alcohol and further processed in paraffin embedding using LEICA PT 1020 Automatic Tissue Processor. About $5 \mu \mathrm{m}$ thick sections of each tissue was stained with hematoxylin and eosin and observed for possible histopathological infiltrations. Microscopic features of the organs of $\mathrm{PB}$-administered rats were then compared with the control group.

\section{Gas chromatographic analysis of PB}

Previously, PB has been characterized to be composed of polysaccharides. ${ }^{4}$ However, the exact constituents of the polysaccharides are yet to be ascertained, hence the need for the current analysis using GC/MS technique. The analysis as earlier reported ${ }^{18}$ essentially involves hydrolysis, 
derivatization and GC/MS characterization. Briefly, the PB (15 mg) was dissolved in $4 \mathrm{~mL}$ of $2 \mathrm{M}$ Trifluoroacetic Acid (TFA) and hydrolyzed at $110^{\circ} \mathrm{C}$ for $4 \mathrm{~h}$ in sealed glass tubes. The hydrolyzed products were then evaporated to dryness under reduced pressure at $50^{\circ} \mathrm{C}$. The residue obtained was dissolved in methanol $(3 \mathrm{~mL})$ and dried over nitrogen gas. The drying was done about 3-4 times to completely remove the TFA. Because of the nonvolatile nature of carbohydrates, the residue was transformed to its volatile derivatives for GC determination. In brief, the hydrolyzed product was dissolved in sterile distilled water $(3 \mathrm{~mL})$ and mixed with sodium borohydride $(25 \mathrm{mg})$. The reduction reaction was performed at room temperature for $3 \mathrm{~h}$ by intermittent agitation. A few drops of glacial acetic acid were added to halt the reaction until no bubbles appeared. The resulting solution was evaporated to dryness under reduced pressure at $50^{\circ} \mathrm{C}$. Methanol $(3 \mathrm{~mL})$ and a stream of nitrogen gas were used to remove the reducing agent 3-4 times and the residue obtained was then dried at $110^{\circ} \mathrm{C}$ for $15 \mathrm{~min}$. Thereafter, the derivatives were mixed with pyridine $(1 \mathrm{~mL})$ and acetic anhydride $(3 \mathrm{~mL})$ over water bath at $100^{\circ} \mathrm{C}$ for $3-5 \mathrm{~h}$. The mixture was evaporated to dryness at $80^{\circ} \mathrm{C}$ and trichloromethane $(5 \mathrm{~mL})$ was added to dissolve the residue. Distilled water was used to wash the organic solution three times to remove ions or extra acetic anhydride. Finally, the water was removed by adding anhydrous sodium sulfate and the supernatant filtered through a $0.45 \mu \mathrm{m}$ membrane prior to GC-MS analysis.

For the GC/MS analysis, Agilent Technologies GC systems model (GC-MS, Agilent HP 6890-5973, USA) was used for the identification and quantification of the sugar constituents of $\mathrm{PB}$. The machine is equipped with capillary column DB-5(60 $\mathrm{m} \times 0.25 \mathrm{~mm}$ I.D., $0.25 \mu \mathrm{m}$ film thickness). Helium was the carrier gas at a flow rate of $1.0 \mathrm{~mL} / \mathrm{min}$. The temperature was programmed as follows: initial temperature $150^{\circ} \mathrm{C}$, maintained $1 \mathrm{~min}$; rise to $250^{\circ} \mathrm{C}$ at a rate of $25^{\circ} \mathrm{C} / \mathrm{min}$, retained for $10 \mathrm{~min}$. The total analysis was conducted in $23 \mathrm{~min}$ and the equilibration time was $2 \mathrm{~min}$. The temperature of the injection port was $250^{\circ} \mathrm{C}$ and $1 \mu \mathrm{L}$ sample was injected in splitless mode. The mass spectrometer was operated in electron ionization mode at an ionizing energy of $70 \mathrm{eV}$, with the temperature of ion source of $230^{\circ} \mathrm{C}$ and the detector was used to scan from $\mathrm{m} / \mathrm{z} 50$ to 500 .

\section{Statistical analysis}

The results are presented as mean \pm standard error of mean (SEM) of replicate determinations and were subjected to one-way Analysis of Variance (ANOVA) complemented with Duncan multiple range test to determine significant differences in all the parameters. Values were considered statistically significant at $p<0.05$.

\section{RESULTS}

\section{Acute oral toxicity of PB}

Neither mortality nor morbidity was observed in the treated animals over the experimental period. There were no signs of changes in the behaviour, fur, pupil dilation, eyes mucous membrane and no evidence of tremor, convulsion, salivation, diarrhea, lethargy, abnormal sleep or coma existed in the tested rats during the first $4 \mathrm{~h}$ of $2000 \mathrm{mg} / \mathrm{kg}$ b.w. of $\mathrm{PB}$ administration and throughout the 2 weeks observation period. The body weight gained by the PB-treated rats was comparable to the control group values (Table 1). The data obtained with respect to the clinical biochemistry and haematological indices showed no significant $(p>0.05)$ treatment-related changes in the treated animals when compared with the control group (Tables 2 and 3). Gross and microscopic examination of the kidney and liver sections from the PB-administered rats revealed no changes attributable to the administration of $\mathrm{PB}$ and the micrographs showed similar profiles as those of the control group (Figure 1).

\section{4-week oral toxicity of PB}

Cage side observations revealed that the once daily oral administration of $\mathrm{PB}$ for 4 weeks at all the investigated concentrations did not induce any treatment-related toxicity in the animals. Neither deaths nor obvious clinical pathological signs were observed and the behavioural activities of the animals were essentially normal throughout the experimental period. The consumption patterns (Figures $2 \mathrm{a}$ and $2 \mathrm{~b}$ ) and the body weight changes in the PB-treated rats competed well with the normal control values and there were no significant $(p>0.05)$ differences in the relative organ-body weight ratios when compared with the control group (Table 4)

Except for the significantly increased $(p<0.05)$ serum activity of ALP at the $500 \mathrm{mg} / \mathrm{kg}$ b.w. PB dose when compared with the control, administration of PB had no significant $(p>0.05)$ effect on other clinical biochemistry as well as lipid profile and haematological parameters investigated (Tables 5, 6 and 7). The macroscopic and microscopic examinations of the kidneys and liver also revealed no significant differences in the architectural integrity of the tissue sections from the PB-administered groups and the control (Figure 3).

\section{GC/MS}

The GC/MS results indicated the presence of 7 peaks corresponding to D-galactose (14.32\%), L-rhamnose (49.83\%), D-ribose (7.32\%), L-arabinose (7.05\%), D-glucosamine (9.94\%), D-glucoronate (7.01\%) and D-fucose (10.53\%) (Figure 4).

\section{DISCUSSION}

Acute toxicity evaluation is an initial step in the safety assessment of unknown substances ${ }^{19}$ and outcomes are imperative to labelling and classifying a chemical on the Globally Harmonised Classification System for Chemical Substances and Mixtures (GHS) OECD..$^{13}$ Based on GHS, PB could be classified as non-acutely toxic when administered via oral route and may be adjudged relatively safe for consumption. Also, since PB at $2000 \mathrm{mg} / \mathrm{kg}$ b.w. was found to be survivable, no further acute testing is recommended. ${ }^{20}$ This observation further supports that $\mathrm{PB}$ did not elicit non-acute toxicity effect at a single oral dose of $2000 \mathrm{mg} / \mathrm{kg}$ b.w. since no treatment-related adverse effects were observed in the experimental rats throughout the 2 weeks observation period. This may also suggest that its $\mathrm{LD}_{50}$ is well above $2000 \mathrm{mg} / \mathrm{kg}$ b.w. in Wistar rats. Although, the result

Table 1: Changes in Body Weight and Relative Organ Weights of the Animals Following Treatment with $2000 \mathrm{mg} / \mathrm{kg}$ Body Weight of PB.

\begin{tabular}{ccccccc} 
& \multicolumn{4}{c}{ Weekly weight changes $(\mathrm{g})$} & \multicolumn{3}{c}{ ROW $(\mathrm{g} / 100 \mathrm{~g})$} \\
\cline { 2 - 6 } Treatments & 0 (initial) & 1 & 2 (final) & \% weight gain & Kidney & Liver \\
\hline Control & $158.44 \pm 4.45$ & $161.33 \pm 3.09$ & $165.34 \pm 3.21$ & 4.17 & $0.75 \pm 0.19$ & $4.55 \pm 0.75$ \\
$2000 \mathrm{mg} / \mathrm{kg}$ & $160.33 \pm 4.02$ & $164.03 \pm 3.35$ & $166.99 \pm 3.35$ & 3.99 & $0.79 \pm 0.25$ & $4.62 \pm 0.46$ \\
\hline
\end{tabular}

$(n=5$, mean \pm SEM). ROW = relative organ weight.

The data obtained with respect to the clinical biochemistry and haematological indices showed no significant $(p>0.05)$ treatment-related changes in the treated animals when compared with the control group (Tables 2 and 3). 
Table 2: Effect of $2000 \mathrm{mg} / \mathrm{kg}$ Body Weight Oral Single Dose Administration of PB on some Kidney and Liver Function Parameters of the Animals.

\begin{tabular}{ccc}
\hline Parameters & Control & $2000 \mathrm{mg} / \mathrm{kg}$ PB \\
\hline Sodium $(\mathrm{mmol} / \mathrm{L})$ & $138.11 \pm 3.01$ & $139.22 \pm 2.55$ \\
Potassium $(\mathrm{mmol} / \mathrm{L})$ & $6.02 \pm 0.01$ & $5.98 \pm 0.02$ \\
Urea $(\mathrm{mmol} / \mathrm{L})$ & $10.12 \pm 1.01$ & $10.05 \pm 0.99$ \\
Uric acid $(\mathrm{mmol} / \mathrm{L})$ & $0.15 \pm 0.01$ & $0.14 \pm 0.01$ \\
Creatinine $(\mu \mathrm{mol} / \mathrm{L})$ & $33.25 \pm 1.02$ & $34.12 \pm 1.35$ \\
Total protein $(\mathrm{g} / \mathrm{L})$ & $60.01 \pm 2.51$ & $59.91 \pm 1.19$ \\
Albumin $(\mathrm{g} / \mathrm{L})$ & $31.03 \pm 0.01$ & $31.10 \pm 0.02$ \\
ALT $(\mathrm{IU} / \mathrm{L})$ & $43.09 \pm 1.76$ & $42.21 \pm 0.98$ \\
AST $(\mathrm{IU} / \mathrm{L})$ & $156.88 \pm 4.50$ & $155.24 \pm 3.79$ \\
ALP $(\mathrm{IU} / \mathrm{L})$ & $645.15 \pm 6.14$ & $640.16 \pm 5.55$ \\
\hline
\end{tabular}

$(\mathrm{n}=5$, mean $\pm S E M)$. Values not sharing superscripts along the same row for each parameter are not significantly different $(p>0.05)$. ALT $=$ Alanine aminotransferase, $\mathrm{AST}=$ Aspartate aminotransferase, $\mathrm{ALP}=$ Alkaline phosphatase, $\mathrm{PB}=$ Purified bioflocculant from A. humicola.

Table 3: Effect of 2000 mg/kg Body Weight Oral Single Dose Administration of PB on Haematological Parameters of the Animals.

\begin{tabular}{ccc}
\hline Parameters & Control & $2000 \mathrm{mg} / \mathrm{kg}$ PB \\
\hline $\mathrm{RBC}\left(\mathrm{x} 10^{12} / \mathrm{L}\right)$ & $8.01 \pm 0.15$ & $7.99 \pm 0.20$ \\
$\mathrm{Hb}(\mathrm{g} / \mathrm{dL})$ & $13.72 \pm 0.20$ & $13.63 \pm 0.22$ \\
$\mathrm{HCT}(\%)$ & $0.37 \pm 0.01$ & $0.36 \pm 0.02$ \\
$\mathrm{MCV}(\mathrm{fl})$ & $65.23 \pm 0.25$ & $65.19 \pm 0.15$ \\
$\mathrm{MCH}(\mathrm{pg})$ & $22.32 \pm 0.09$ & $22.11 \pm 0.01$ \\
$\mathrm{MCHC}(\mathrm{g} / \mathrm{dL})$ & $31.92 \pm 0.14$ & $30.99 \pm 0.35$ \\
RDW $(\%)$ & $12.09 \pm 0.15$ & $11.91 \pm 0.05$ \\
WBC $\left(\mathrm{x} 10^{9} / \mathrm{L}\right)$ & $6.09 \pm 0.01$ & $5.59 \pm 0.01$ \\
Lymphocytes $\left(x 10^{9} / \mathrm{L}\right)$ & $6.12 \pm 0.03$ & $6.19 \pm 0.05$ \\
Monocytes $\left(x 10^{9} / \mathrm{L}\right)$ & $0.04 \pm 0.01$ & $0.05 \pm 0.01$ \\
Neutrophils $\left(\mathrm{x} 10^{9} / \mathrm{L}\right)$ & $0.69 \pm 0.01$ & $0.70 \pm 0.01$ \\
Platelet $\left(\mathrm{x} 10^{9} / \mathrm{L}\right)$ & $867.11 \pm 5.32$ & $863.23 \pm 8.01$ \\
\hline
\end{tabular}

$(n=5$, mean \pm SEM). Values not sharing superscripts along the same row for each parameter not significantly different $(p>0.05) . \mathrm{RBC}=$ Red Blood Cell, $\mathrm{Hb}=$ Haemoglobin, $\mathrm{HCT}=$ Hematocrit, $\mathrm{MCV}=$ Mean Corpuscular Volume, $\mathrm{MCH}=$ Mean Corpuscular Hemoglobin, $\mathrm{MCHC}=$ Mean Corpuscular Haemoglobin Concentration, RDW $=$ Red Blood Cell Distribution Width and WBC $=$ White Blood Cell, $\mathrm{PB}=$ Purified Bioflocculant from A. humicola.

ability of the organ, a reduction could be suggestive of cellular constriction. In this study, the non-significant changes in the body weight and the relative organ-body weight ratios of all the $\mathrm{PB}$-administered rats when compared with the control animals may indicate that $\mathrm{PB}$ did not negatively influence the normal metabolism and mechanisms controlling the growth and development of the animals. It also implies that the investigated organs (Kidneys and liver) were neither adversely affected nor elicited clinical symptoms of toxicity throughout the 4 weeks of daily dose treatments with $\mathrm{PB}$. In addition to been suggestive of the unlikely toxic effect of $\mathrm{PB}$ to these organs at the investigated doses, it also supports its potential applicability as a flocculant disinfectant for water treatment. This observation is consistent with the findings of ${ }^{23}$ where the biopolymer extract from $K$. terrigena was confirmed safe and fit for use as a bioflocculant for water treatment following its toxicological evaluation in experimental animals.

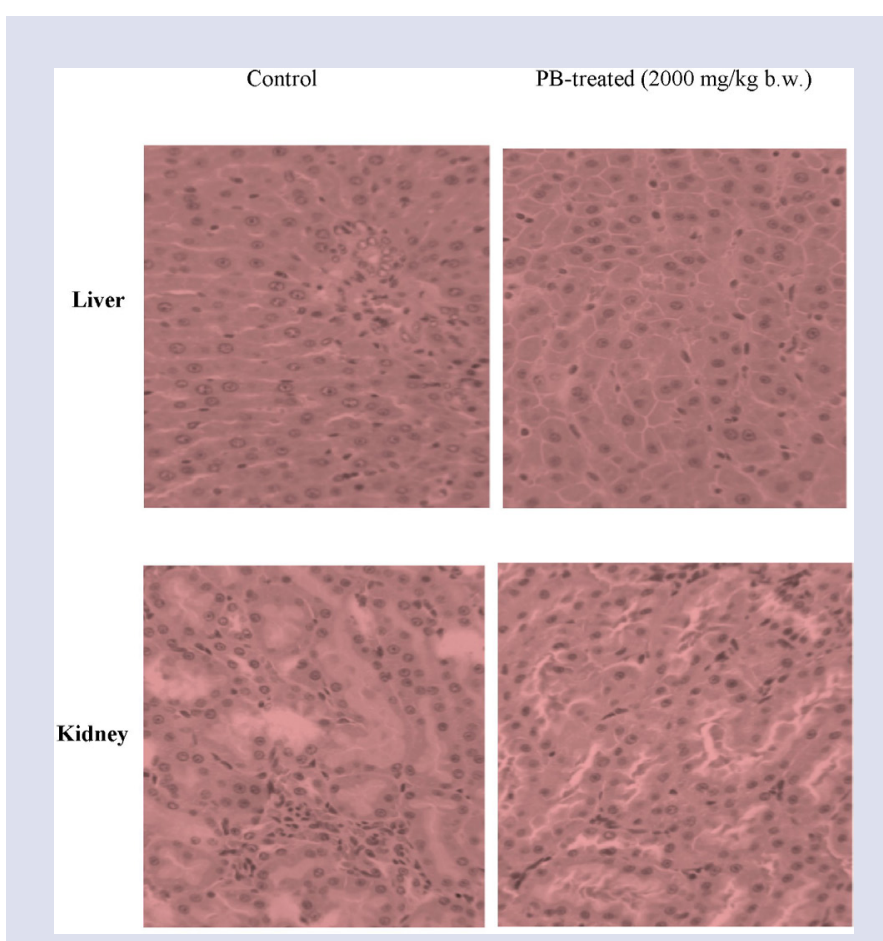

Figure 1: Light Micrographs (400x, Hematoxylin + Eosin Stained) of Tissue Sections of the Kidney and Liver of the Animals Treated with $2000 \mathrm{mg} / \mathrm{kg}$ Body Weight Single Oral Dose of Purified Bio flocculant from A. humicola as Compared to Control.

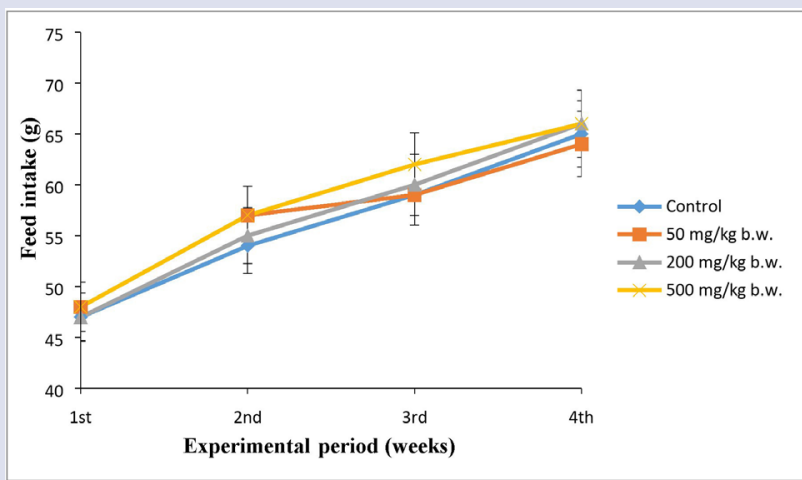

Figure 2a

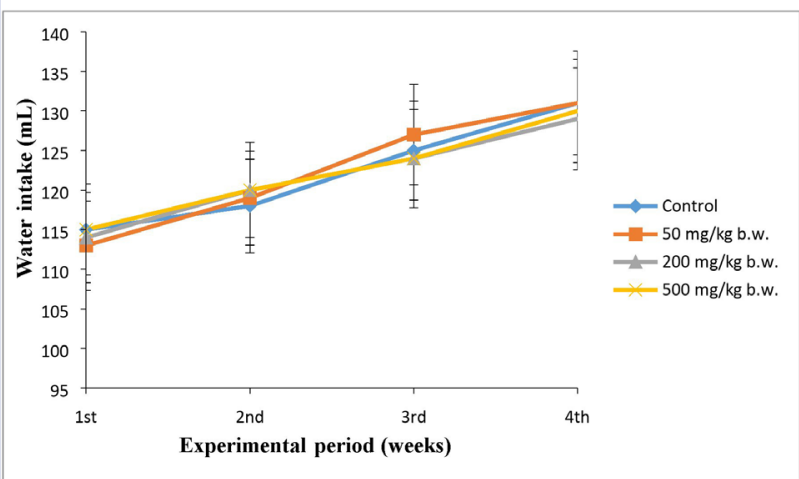

Figure 2: Effect of PB Treatment on (a) Feed and (b) Water Intake of the Animals over 4 weeks Experimental Period. 
Agunbiade, et al.: Safety Assessment of Arthrobacter humicola Bioflocculant

Table 4: Changes in Body Weight (g) and Relative Organ-Body Weight Ratios of the Animals Following Treatment with PB for 4 Weeks.

\begin{tabular}{ccccc}
\hline \multirow{2}{*}{ Week } & \multicolumn{4}{c}{ PB (mg/kg body weight) } \\
\cline { 2 - 5 } & Control & 50 & 200 & 500 \\
\hline 0 (initial) & $150.29 \pm 3.04$ & $157.23 \pm 2.12$ & $160.99 \pm 4.01$ & $160.75 \pm 1.01$ \\
1 & $151.23 \pm 3.25$ & $158.01 \pm 3.34$ & $163.09 \pm 2.33$ & $163.08 \pm 1.11$ \\
2 & $153.02 \pm 2.99$ & $160.34 \pm 2.56$ & $164.17 \pm 3.12$ & $166.14 \pm 1.04$ \\
3 & $158.03 \pm 3.33$ & $166.33 \pm 3.01$ & $169.44 \pm 3.20$ & $168.39 \pm 1.05$ \\
4 (final) & $162.12 \pm 2.45$ & $169.25 \pm 2.45$ & $173.12 \pm 4.06$ & $172.99 \pm 1.03$ \\
Weight gain (\%) & 7.30 & 7.10 & 7.01 & 7.07 \\
RKBW (g/100 g) & $0.81 \pm 0.01$ & $0.85 \pm 0.32$ & $0.88 \pm 0.87$ & $0.88 \pm 0.25$ \\
RLBW (g/ 100 g) & $4.59 \pm 0.56$ & $4.82 \pm 0.75$ & $4.99 \pm 0.57$ & $4.99 \pm 0.56$ \\
\hline
\end{tabular}

$(n=5$, mean \pm SEM $)$. RKBW = Relative kidney-body weight, RLBW= Relative liver-body weight.

Table 5: Effect of 28 Days Repeated Oral Dose Administration of PB on some Kidney and Liver Function Parameters of the Animals.

\begin{tabular}{ccccc}
\hline & & \multicolumn{3}{c}{ PB (mg/kg body weight) } \\
\cline { 3 - 5 } Parameters & Control & 50 & 200 & 500 \\
\hline Sodium $(\mathrm{mmol} / \mathrm{L})$ & $139.05 \pm 2.05$ & $140.02 \pm 1.98$ & $140.10 \pm 2.02$ & $140.05 \pm 1.25$ \\
Potassium $(\mathrm{mmol} / \mathrm{L})$ & $5.33 \pm 0.02$ & $5.33 \pm 0.01$ & $5.38 \pm 0.02$ & $5.40 \pm 0.02$ \\
Urea $(\mathrm{mmol} / \mathrm{L})$ & $9.80 \pm 0.07$ & $10.05 \pm 0.03$ & $10.15 \pm 0.01$ & $10.01 \pm 0.02$ \\
Urate $(\mathrm{mmol} / \mathrm{L})$ & $0.10 \pm 0.02$ & $0.10 \pm 0.02$ & $0.09 \pm 0.01$ & $0.10 \pm 0.01$ \\
Creatinine $(\mu \mathrm{mol} / \mathrm{L})$ & $30.88 \pm 1.01$ & $30.50 \pm 0.99$ & $31.01 \pm 0.89$ & $30.67 \pm 1.10$ \\
Total protein $(\mathrm{g} / \mathrm{L})$ & $55.19 \pm 2.01$ & $56.16 \pm 1.98$ & $56.06 \pm 1.75$ & $56.12 \pm 1.87$ \\
Albumin $(\mathrm{g} / \mathrm{L})$ & $32.01 \pm 0.99$ & $31.75 \pm 0.75$ & $31.89 \pm 0.25$ & $32.05 \pm 0.33$ \\
ALT $(\mathrm{IU} / \mathrm{L})$ & $41.78 \pm 1.35$ & $41.63 \pm 0.86$ & $40.96 \pm 1.82$ & $41.05 \pm 1.22$ \\
AST $(\mathrm{IU} / \mathrm{L})$ & $147.21 \pm 3.35$ & $149.01 \pm 2.75$ & $148.03 \pm 3.10$ & $147.99 \pm 3.05$ \\
ALP $(\mathrm{IU} / \mathrm{L})$ & $636.66 \pm 4.16^{\mathrm{a}}$ & $637.05 \pm 5.05^{\mathrm{a}}$ & $636.50 \pm 4.32^{\mathrm{a}}$ & $647.01 \pm 4.02^{\mathrm{b}}$ \\
\hline
\end{tabular}

$(n=5$, mean $\pm \mathrm{SEM})$. abValues bearing different superscripts along the same row for each parameter are significantly different $(p<0.05)$. ALT $=$ Alanine aminotransferase, $\mathrm{AST}=$ Aspartate aminotransferase, $\mathrm{ALP}=$ Alkaline phosphatase.

Table 6: Effect of 28 Days Repeated Oral Dose Administration of PB on Haematological Parameters of the Animals.

\begin{tabular}{ccccc}
\hline & \multicolumn{4}{c}{ PB (mg/ kg body weight) } \\
\cline { 2 - 5 } Parameters & Control & 50 & 200 & 500 \\
\hline Total cholesterol (mmol/L) & $1.42 \pm 0.10$ & $1.41 \pm 0.15$ & $1.43 \pm 0.32$ & $1.42 \pm 0.25$ \\
Triglycerides (mmol/L) & $0.75 \pm 0.02$ & $0.73 \pm 0.01$ & $0.73 \pm 0.03$ & $0.74 \pm 0.05$ \\
HDL-C (mmol/L) & $0.60 \pm 0.02$ & $0.60 \pm 0.01$ & $0.60 \pm 0.02$ & $0.61 \pm 0.01$ \\
LDL-C (mmol/L) & $0.51 \pm 0.03$ & $0.50 \pm 0.02$ & $0.51 \pm 0.01$ & $0.51 \pm 0.01$ \\
\hline
\end{tabular}

$(n=5$, mean \pm SEM $)$. HDL-C $=$ High density lipoprotein cholesterol, LDL-C $=$ Low density lipoprotein cholesterol.

of this evaluation is not intended to determine the exact $\mathrm{LD}_{50}$ value, it has given a baseline prediction on the no-observed-adverse-effect level of $\mathrm{PB}$ dose at which the animals are expected to survive without obvious clinical pathological manifestations. Furthermore, the no substance-related changes in the body weight, relative organ weights, hematological and clinical biochemistry parameters of the treated animals to this high dose treatment are another supportive fact justifying the non-toxic effect of PB.
Table 7: Effect of 28 Days Daily Dose of PB on Lipid Profiles of the Animals.

\begin{tabular}{ccccc}
\hline \multirow{2}{*}{ Parameters } & \multicolumn{4}{c}{ PB (mg/kg body weight) } \\
\cline { 2 - 5 } & Control & 50 & 200 & 500 \\
\hline RBC (x1012/L) & $6.98 \pm 0.15$ & $7.05 \pm 0.12$ & $7.04 \pm 0.12$ & $6.99 \pm 0.14$ \\
Hb (g/dL) & $13.95 \pm 0.25$ & $13.83 \pm 0.22$ & $14.10 \pm 0.15$ & $13.99 \pm 0.31$ \\
HCT (\%) & $0.35 \pm 0.01$ & $0.35 \pm 0.03$ & $0.36 \pm 0.01$ & $0.36 \pm 0.02$ \\
MCV (fl) & $62.12 \pm 0.99$ & $61.95 \pm 0.85$ & $62.25 \pm 0.85$ & $62.09 \pm 0.55$ \\
MCH (pg) & $22.76 \pm 0.15$ & $22.50 \pm 0.11$ & $22.75 \pm 0.19$ & $21.99 \pm 0.43$ \\
MCHC (g/dL) & $30.21 \pm 1.01$ & $31.00 \pm 0.99$ & $30.99 \pm 0.11$ & $31.08 \pm 0.15$ \\
RDW (\%) & $10.98 \pm 0.01$ & $11.04 \pm 0.05$ & $10.89 \pm 0.05$ & $11.01 \pm 0.03$ \\
WBC (x10\%/L) & $5.72 \pm 0.05$ & $5.45 \pm 0.05$ & $5.63 \pm 0.02$ & $5.76 \pm 0.05$ \\
Lymphocytes(x10 $/ \mathrm{L})$ & $6.10 \pm 0.01$ & $6.03 \pm 0.01$ & $5.89 \pm 0.01$ & $6.08 \pm 0.01$ \\
Monocytes (x10 $/ \mathrm{L})$ & $0.05 \pm 0.01$ & $0.05 \pm 0.01$ & $0.06 \pm 0.01$ & $0.06 \pm 0.01$ \\
Neutrophils (x10 $/ \mathrm{L})$ & $0.71 \pm 0.02$ & $0.70 \pm 0.01$ & $0.69 \pm 0.01$ & $0.71 \pm 0.01$ \\
Platelet (x10 $/ \mathrm{L})$ & $870.02 \pm 7.05$ & $869.07 \pm 6.56$ & $869.33 \pm 7.05$ & $872.05 \pm 7.45$ \\
\hline
\end{tabular}

$(n=5$, mean \pm SEM). RBC= Red blood cell, $\mathrm{Hb}=$ Haemoglobin, HCT $=$ Hematocrit, $\mathrm{MCV}=$ Mean corpuscular volume, $\mathrm{MCH}=$ Mean corpuscular hemoglobin, $\mathrm{MCHC}=$ Mean corpuscular haemoglobin concentration, $\mathrm{RDW}=$ Red blood cel distribution width and $\mathrm{WBC}=$ White blood cell.

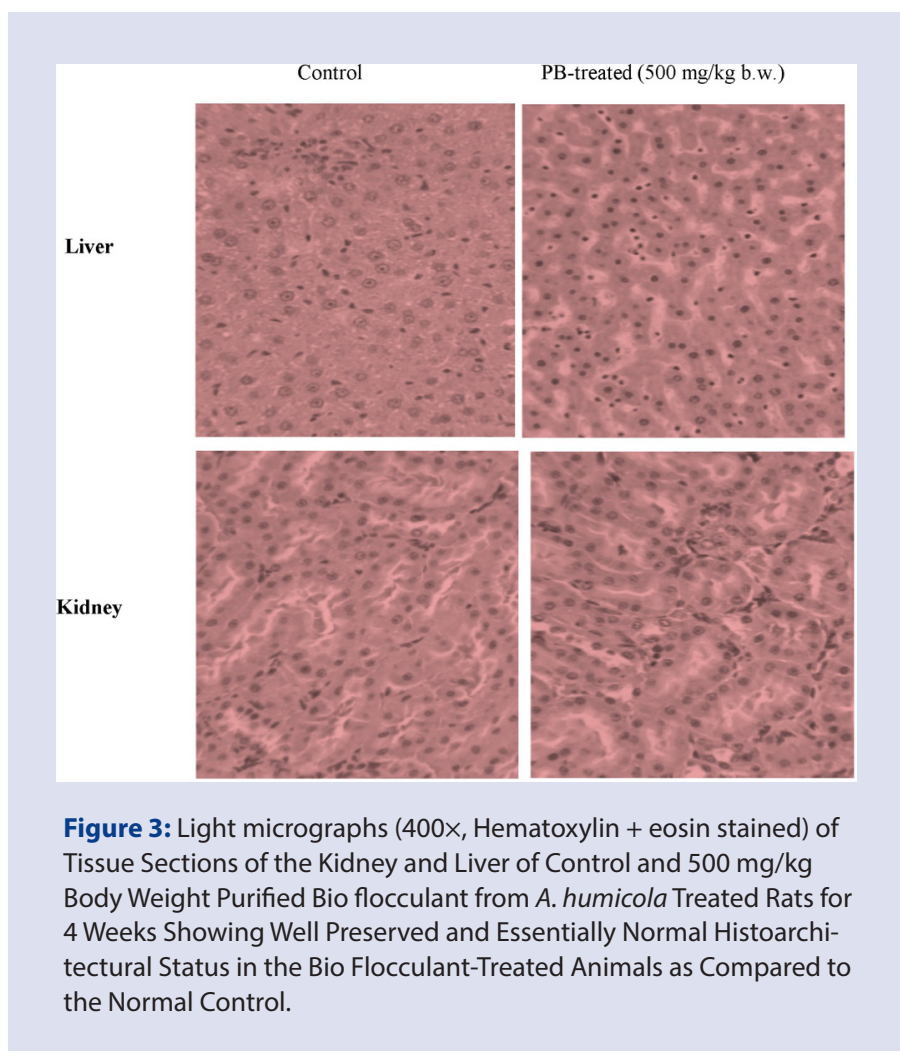

Similarly, that the daily 4 weeks administration of PB caused no clinical signs for morbidity, toxicity or mortality across all the treatment groups may be suggestive of its unlikely toxic effect at the tested doses over the investigation period. A change in body weight is one of the first critical signs of toxicity and may serve as sensitive indication of the overall health status of animals. ${ }^{21}$ The importance of relative organ weight in toxicity studies is germane to unravelling obvious treatment-induced organ weight variations in experimental animals. ${ }^{22}$ While an increase in organ-body weight may either depict inflammation or increased secretory 


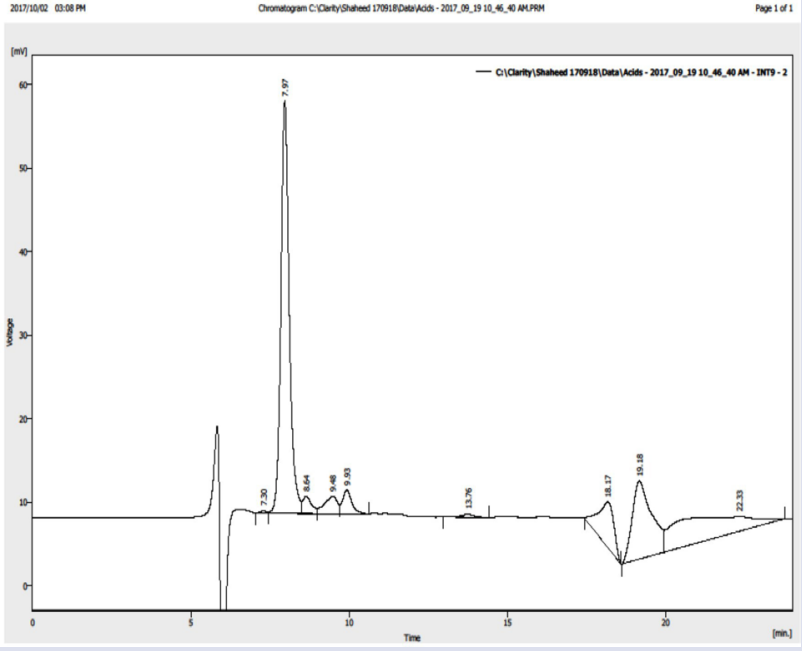

Figure 4: GC-MS Chromatogram of the Polysaccharide Constituents of Purified Bio Flocculant from A. humicola.

Also, the non-significant difference in RBCs, Hb, WBC, PLT and all the other hematopoietic indices following once daily dose administration of $\mathrm{PB}$ might be an indication that it may not be toxic to the blood. For instance, this could either specifically mean that the incorporation of $\mathrm{Hb}$ into RBCs as well as osmotic fragility and morphology of the RBCs was intact or the oxygen-carrying role of the $\mathrm{Hb}$ and amount of oxygen delivered to the target tissues of the animals were not impacted subsequent to treatment with PB. Analyses on other indices (HCT, MCV, $\mathrm{MCH}, \mathrm{MCHC}$ and RDW) relating to the status of RBCs may be crucial in defining anemic condition in animals. ${ }^{16}$ That administration of $\mathrm{PB}$ did not elicit any treatment-related changes on these indicators is suggestive of its non-adverse effect on RBCs' microcytes and $\mathrm{Hb}$ weight per RBCs. This indicates that the 4-week daily oral dose treatment with PB does not predispose the animals to anemic condition throughout the evaluation period and further support the safety use of PB as a bioflocculant. This is in agreement with previous studies. ${ }^{23,9}$ The authors opined that a 28-day treatment with purified bioflucculants from microbes elicited non-hematotoxic effect on the experimental animals and suggested the bioflocculants as void of toxic tendency and with potential use in water treatment for consumption.

Clinical biochemistry analyses were performed to evaluate the possible changes in the kidney and liver functions that might have been induced by $\mathrm{PB}$ administration. In the present study, the non-significant difference observed in the kidney and liver function parameters in the PB-treated animals is suggestive of preserved or normal functions of these organs and further lent credence to the non-toxic tendency of $\mathrm{PB}$. Although, the observed significantly high serum activity of ALP in the rats treated with $500 \mathrm{mg} / \mathrm{kg}$ b.w. PB may seem to indicate that exposure to daily repeated doses above $500 \mathrm{mg} / \mathrm{kg}$ b.w. may result in slight liver damage, this is however not consistent with the results of other liver function indices as well as the reports of the histopathological examination. Additionally, alteration in the concentration of lipids like TC, HDL-C, LDL-C and TG can give useful information on lipid metabolism as well as predisposition of the heart to atherosclerosis and its associated coronary heart diseases. ${ }^{24} \mathrm{TG}, \mathrm{LDL}-\mathrm{C}$ and HDL-C are associated with lipolysis, carrier of plasma cholesterol and atherosclerotic tendency, respectively. ${ }^{25}$ The non-significant changes in the serum levels of these parameters in the $\mathrm{PB}$-administered rats relative to the control group could suggest that $\mathrm{PB}$ may not predispose the animals to cardiovascular risk and further supportive of its safety profile.

Another formidable consideration in evaluating the safety of a substance against organ injury is its effects on histology. The effects are manifestations of inflammatory damage on the studied organ and often complement the reports of hematological and clinical biochemistry analyses. ${ }^{26}$ Therefore, the well preserved colour and texture of the kidneys and liver as evident from macroscopic examinations in this study is another tenable fact that the organs were void of injuries and further suggests that $\mathrm{PB}$ was not toxic to them at the investigated regimens. Furthermore, the no treatment-induced inflammations and derangements as revealed in the detailed microscopic examination of the organs from PB-treated groups is not only supportive of its tolerability by the organs, but also its fitness for healthy use.

The occurrence of carboxyl and hydroxyl functional groups in a bioflocculant suggests adsorption positions for suspended particles and has been opined to be the best choice of functional groups for flocculation process. ${ }^{27}$ Interestingly, our previous report on the biochemical analyses of PB showed that it is polysaccharide-endowed and has hydroxyl, carboxyl and uronate as its main functional groups ${ }^{4}$ thus, corroborating the current assertion of the identification of the various monosaccharides with these unique functional groups. Therefore, it may be logically inferred that, besides being safe, the GC/MS analysis of $\mathrm{PB}$ also revealed that it is rich in monomers bearing significant functional groups of utmost importance in bioflocculation and stand a chance as a potential new lead candidate in water treatment.

\section{CONCLUSION}

From the results of this study, it can be concluded that treatment with PB neither caused morbidity, lethality nor any obvious pathological changes in all the parameters investigated and thus, may be adjudged relatively safe for consumption. Although, its continuous usage above $500 \mathrm{mg} / \mathrm{kg}$ b.w. dose seems to potentiate slight hepatic infiltration, the overall assessment of $\mathrm{PB}$ indicates that it is not toxic and is endowed with monomers bearing functional groups of flocculation importance, hence, suggesting its potential application for water treatment.

\section{CONFLICT OF INTEREST}

The authors no conflict of interest.

\section{ABBREVIATIONS}

PB: Purified bioflocculant; TG: Triacylglycerides; LDL-C: Low-density lipoprotein cholesterol; HDL-C: High-density lipoprotein cholesterol; ALT: Alanine aminotransferase; ALT: Aspartate aminotransaminase; ALP: Alkaline phosphatase; GHS: Globally Harmonised Classification System; GCMS: Gas chromatography mass spectrometry; RBC: Red blood cell count; HCT: Haemoglobin concentration; MCH: Mean corpuscular haemoglobin; WBC: White blood cell count; EDTA: Ethylene diamine tetraacetic acid; LD: Lethal dose; OECD: Organization of economic cooperation and development; NIH: National Institute of health; NRC: National research council.

\section{REFERENCES}

1. Xia SZ, Zhang $X$, Wang A, Yang L, Chen J, Zhao, et al. Production and characterization of bioflocculant by Proteus mirabilis TJ-1. Bioresour Technol. 2008;99(14):6520-7.

2. Aljuboori AHR, Uemura Y, Osman NB, Yusup S. Production of a bioflocculant from Aspergillusniger using palm oil mill effluent as carbon source. Bioresour Technol. 2014;171:66-70.

3. Bala SS, Yan S, Tyagi RD, Surampalli RY. Extracellular Polymeric Substances (EPS) producing bacterial strains of municipal wastewater sludge: isolation, molecular identification, EPS characterization and performance for sludge 
settling and dewatering. Water Res. 2010;44(7):2253-63.

4. Agunbiade $\mathrm{MO}$, Esta $\mathrm{VH}$, Pohl $\mathrm{CH}$, Ashafa AOT. Flocculating performance of a bioflocculant produced by Arthrobacter humicola in sewage wastewater treatment BMC Biotechnol. 2017;17(1):51. DOI 10.1186/s12896-017-0375-0.

5. Zhao H, Liu H, Zhou J. Characterization of a bioflocculant MBF-5 by Klebsiella pneumonia and its application in Acanthamoeba cysts removal. Bioresour Technol. 2013;137:226-32.

6. Oh HM, Lee SJ, Park MH, Kim HS, Kim HC. Harvesting of Chlorella vulgaris using a bioflocculant from Paenibacillus sp. AM49. Biotechnol Lett. 2001;23(15):1229-34.

7. Zhang ZQ, Xia SQ, Zhao SQ, Zhang JF. Characterization and flocculation mechanism of high efficiency microbial flocculant TJ-F1 from Proteus mirabilis. Colloids Sur B Biointerf. 2010;75(1):247-51

8. Yang Q, Luo K, Liao D, Li X, Wang D, Liu X, et al. A novel bioflocculant produced by Klebsiella sp. and its application to sludge dewatering. Water Environ J. 2012;26(4):560-6.

9. Chen H, Zhong C, Berkhouse H, Zhang Y, LvY, LuW, et al. Removal of cadmium by bioflocculant produced by Stenotrophomonas maltophilia using phenolcontaining wastewater. Chemosphere. 2016;155:163-9.

10. Piyo N, Cosa S, Mabinya LV, Okoh Al. Assessment of bioflocculant production by Bacillus sp. Gilbert, a marine bacterium isolated from the bottom sediment of Algoa Bay. Mar Drugs. 2011;9(7):1232-42.

11. National Institute of Health (NIH). Care and Use of Laboratory Animals. National Institute of Health Publication. 1985;85.

12. National Research Council (NRC). Guide for the Care and Use of Laboratory Animals: $8^{\text {th }}$ Ed. in: Guide for the Care and Use of Laboratory Animals. National Research Council. 2011;118

13. Organization of Economic Co-Operation and Development (OECD). Guideline for testing of chemicals, acute oral toxicity- acute toxicity class method. 2001;423.

14. Ajani EO, Sabiu S, Bamisaye FA, Ibrahim S, Salau BA. Evaluation of the acute and sub-acute toxicity effect of ethanolic leaves extract of Lagenaria breviflora (Bitter gourd) on hepatic and renal function of rats. J of Pharmacy and Biol Sci. 2014;9:61-8.

15. Organization of Economic Co-Operation and Development (OECD). Report of the validation of the updated test guideline 407: Repeat dose 28-day oral toxicity study in laboratory rats. Series on testing and assessment No 59, ENV/JM/ MONO. 2006;26.

16. Sabiu S, Ajani EO, Abubakar AA, Sulyman AO, Nurain IO, Irondi AE, et al. Toxicological evaluations of Stigma maydis aqueous extract on hematological and lipid parameters of Wistar rats. Tox Rep. 2015;2:638-44.

17. Drury RAB, Wallington EA. Carleton's Histological Techniques $5^{\text {th }}$ edition. Oxford University Press. 1980;36-148.

18. Guadalupe Z, Martínez-Pinilla O, Garrido Á, Carrillo JD, Ayestarán B. Quantitative determination of wine polysaccharides by Gas Chromatography-Mass Spectrometry (GC-MS) and Size Exclusion Chromatography (SEC). Food Chem. 2012;131(1):367-74.

19. Lorke D. A new approach to practical acute toxicity testing. Achieves of Toxicology. 1983;54(4):275-87.

20. National Research Council (NRC). Toxicity testing for assessing environmenta agents, Interim Report, National Academies Press, Washington DC, USA. 2006.

21. Sireatawong S, Lertprasertsuke N, Srisawat U. Acute and sub-chronic toxicity study of the water extract from Tiliacora trianora (Colebr.) Diels in rats. Songklankarin J of Sci and Tech. 2008;30(6):729-37.

22. Wooley A. A guide to practical toxicology evaluation, prediction and risk determination- General and reproductive toxicology. Taylor and Francis, New York. 2003;80-106.

23. Khaira GK, Ganguli A, Ghosh A. Antimicrobial efficacy and in vivo toxicity studies of a quaternized biopolymeric flocculant. J of Water and Health. 2014;12(4):656-62.

24. Ajani EO, Sabiu S, Bamishaye FA. A 4-week daily dose oral administration assessment of Cyperus esculentus L. aqueous extract on key metabolic markers of Wistar rats. Pharmacologia. 2016;7:125-33.

25. Oyedemi SO, Yakubu MT, Afolayan AJ. Effect of aqueous extract of Leonotis leonorus (L.) leaves in male Wistar rats. Hum Exp Toxicol. 2010;29(5):377-84.

26. Sabiu S, O'Neil FH, Ashafa AOT. Toxicopathological evaluation of a 28-day repeated dose administration of Zea mays L. (Poaceae), Stigma maydis aqueous extract on key metabolic markers of Wistar rats. Trans R Soc S Afr. 2017;72(3):225-33.

27. Daolun LF, Shinhong HX. Characterization of bioflocculant MBF33-3 produced by an isolated Bacillus sp. World J Microbiol Biotechnol. 2008;24(9):1627-32.

\section{GRAPHICAL ABSTRACT}

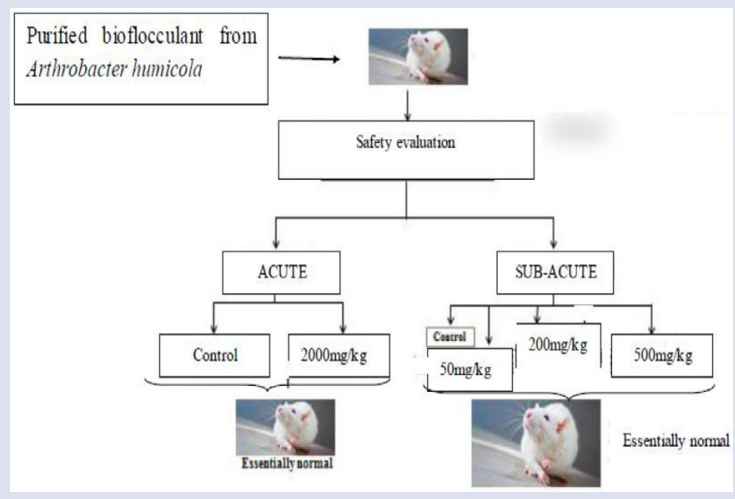

\section{SUMMARY}

- The Purified Bioflocculant (PB) from Arthrobacter humicola was evaluated for toxicological effect in Wistar rats.

- The monosaccharide constituents of PB was also chromatographically analysed.

- The no-observed-adverse-effect level of PB was estimated to be above 2000 $\mathrm{mg} / \mathrm{kg}$ b.w.

- The overall results suggested that PB was well tolerated by the animals and is endowed with monosaccharides bearing functional groups of flocculation importance.

- This ultimately suggests the potential application of PB as a safe actinomycetes bioflocculant for water treatment.

Cite this article: Agunbiade MO, Saheed S, Heerden EV, Pohl CH. In vivo Toxicopathological Evaluation of a Purified Bioflocculant Produced by Arthrobacter humicola. Pharmacog J. 2019;11(3):486-92. 